\title{
Quantitative Determination of the Enantiomeric Composition of Panthotenic Acid Solutions: A Mass Spectrometry Experiment
}

\author{
Daniella V. Augusti, Rochel M. Lago and Rodinei Augusti* \\ Departamento de Química, Universidade Federal de Minas Gerais, Av. Antonio Carlos, 6627, Pampulha, 31270-901 \\ Belo Horizonte - MG, Brazil
}

\begin{abstract}
Determinações rápidas e quantitativas da composição enantiomérica de soluções de ácido pantotênico foram realizadas pela utilização da ionização do tipo "electrospray" e da espectrometria de massas seqüencial e através da aplicação do método cinético para realizar a análise dos dados. Desvios da ordem de $1 \%$, entre os valores reais e experimentais das composições enantioméricas, foram observados.
\end{abstract}

Rapid and quantitative determinations of the enantiomeric compositions of pantothenic acid solutions were carried out by using electrospray ionization tandem mass spectrometry and applying the kinetic method to perform the data analysis. Deviations of $c a .1 \%$ between the actual and experimental enantiomeric compositions were observed.

Keywords: pantothenic acid, enantiomeric composition, electrospray ionization, tandem mass spectrometry, kinetic method

\section{Introduction}

Pantothenic acid belongs to the group of B vitamins and, as a constituent of coenzyme A, plays a key role in the metabolism of carbohydrates, proteins and fats, and is therefore important for the maintenance and repair of all cells and tissue. It is involved in reactions that supply energy, in the synthesis of vital compounds as sterols (cholesterol), hormones (growth, stress and sex hormones), neurotransmitters (acetylcholine), phospholipids (components of cell membranes), porphyrin (component of hemoglobin, the oxygen-carrying red blood cell pigment), antibodies, and in the metabolism of drugs (sulfonamides). It also stimulates the adrenal glands and increases the production of cortisone for healthy nerves and skin. It has been verified, however, that only the Denantiomer, its naturally-occurring form, has vitamin activity. The L-form, L-pantothenic acid, has been shown to have an antagonistic effect in animal studies. ${ }^{1}$

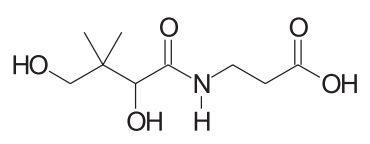

pantothenic acid

* e-mail: augusti@dedalus.lcc.ufmg.br
There are few issues in chemistry that has drawn as much attention as the chiral nature of molecules. For instance, systematic examination of the biological activity of individual enantiomers is the rule for all new racemic drug candidates, and an increasing number of optically pure drugs has been approved and marketed. ${ }^{2}$

Noteworthy advance has been made during the past few years on general methods of chiral identification and quantification ${ }^{3}$ based entirely on mass spectrometry. It is possible to group the methods used for chiral recognition and for quantification of enantiomeric excess by mass spectrometry into four wide types: (a) generation of hostguest diasteromeric adducts using a chiral guest: ${ }^{4,5}$ (b) determination of rates of ion/molecule reactions between an enantiomeric guest and a host molecule; ${ }^{6}$ (c) collisioninduced dissociation (CID) of diasteromeric adducts in a MS/MS experiment; 7 (d) utilization of the kinetic method $^{8-12}$ to quantify the MS/MS chiral effect. ${ }^{13}$ This last methodology has been successfully applied to quantitative analysis of aminoacids, ${ }^{13,14} \alpha$-hydroxyacids, ${ }^{15}$ sugars ${ }^{16}$ and some drugs ${ }^{17-19}$ and has been shown to be fast and to require very small amounts of sample.

The chiral distinction based on the kinetic method approach, the subject of this paper, involves, as the first step, the choice of systems that can promote acceptable enantiomeric distinction. In order to do that, the singly-charged 
trimeric complexes, $\left[\mathrm{M}\left(\mathrm{ref}^{*}\right)\left(\mathrm{A}_{\mathrm{D}}\right)_{2}-\mathrm{H}\right]^{+}$or $\left[\mathrm{M}\left(\mathrm{ref}^{*}\right)\left(\mathrm{A}_{\mathrm{L}}\right)_{2}-\mathrm{H}\right]^{+}$ - formed in an electrosprayed solution containing a chiral analyte ( $A_{D}$ or $A_{L}$, respectively), a chiral reference compound $\left(\mathrm{ref}^{*}\right)$, and a metal cation (usually $\mathrm{M}^{2+}$ ) - are mass-selected and fragmented upon collision-induced dissociation. Scheme 1 displays the competitive dissociation of both trimeric complexes to form the corresponding dimeric fragments, i.e. $\left[\mathrm{M}\left(\mathrm{ref}^{*}\right)\left(\mathrm{A}_{\mathrm{D}(\mathrm{L})}\right)-\mathrm{H}\right]^{+}$and $\left[\mathrm{M}\left(\mathrm{A}_{\mathrm{D}(\mathrm{L})}\right)_{2}-\mathrm{H}\right]^{+}$.

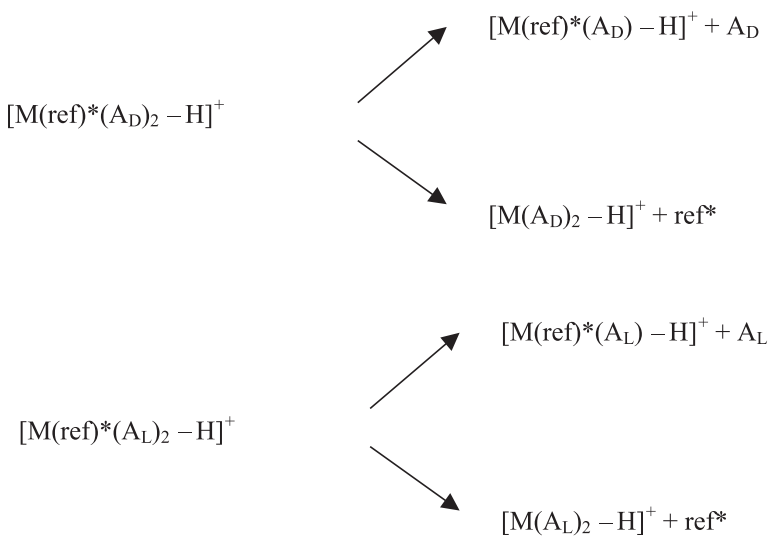

Scheme 1.

Scheme 2 shows the energy diagram for the competitive dissociations of the trimeric complexes $\left[\mathrm{M}\left(\mathrm{ref}^{*}\right)\left(\mathrm{A}_{\mathrm{D}}\right)_{2}-\mathrm{H}\right]^{+}$ and $\left[\mathrm{M}(\mathrm{ref} *)\left(\mathrm{A}_{\mathrm{L}}\right)_{2}-\mathrm{H}\right]^{+}$to form the corresponding dimeric fragments. Note that the dimeric complexes $\left[\mathrm{M}\left(\mathrm{A}_{\mathrm{D}}\right)_{2}-\mathrm{H}\right]^{+}$ and $\left[\mathrm{M}\left(\mathrm{A}_{\mathrm{L}}\right)_{2}-\mathrm{H}\right]^{+}$are enantiomers and, therefore, possess exactly the same energy level.

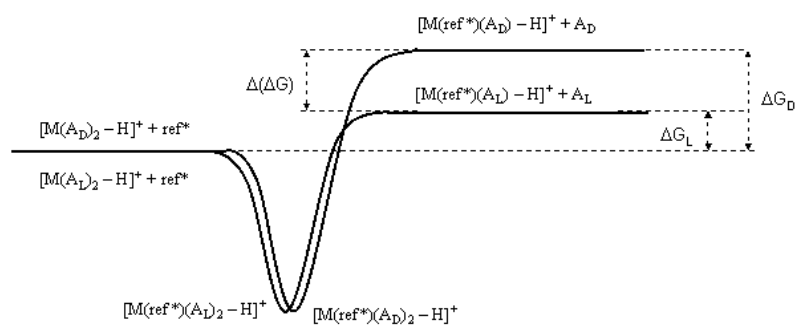

Scheme 2.

Clearly the difference in energy between the diasteromeric complexes $\left[M\left(\mathrm{ref}^{*}\right)\left(\mathrm{A}_{\mathrm{D}}\right)-\mathrm{H}\right]^{+}$and $\left[\mathrm{M}\left(\mathrm{ref}^{*}\right)\left(\mathrm{A}_{\mathrm{L}}\right)\right.$ $\mathrm{H}]^{+}$results in differences in their rates of formation and hence in the relative abundance ratios $\left(\mathrm{R}_{\mathrm{D}}\right.$ or $\left.\mathrm{R}_{\mathrm{L}}\right)$ for the $\mathrm{D}$ and $\mathrm{L}$ isomers, defined in equations 1 and 2, respectively:

$\mathrm{R}_{\mathrm{D}}=\left[\mathrm{M}(\mathrm{ref} *)\left(\mathrm{A}_{\mathrm{D}}\right)-\mathrm{H}\right]^{+} /\left[\mathrm{M}\left(\mathrm{A}_{\mathrm{D}}\right)_{2}-\mathrm{H}\right]^{+}$

$\mathrm{R}_{\mathrm{L}}=\left[\mathrm{M}(\mathrm{ref} *)\left(\mathrm{A}_{\mathrm{L}}\right)-\mathrm{H}\right]^{+} /\left[\mathrm{M}\left(\mathrm{A}_{\mathrm{L}}\right)_{2}-\mathrm{H}\right]^{+}$

The ratio of the individual ratios, $R_{D}$ to $R_{L}$, defined as $R_{\text {chiral }}$ (equation 3), indicates the level of chiral distinction achievable in a particular experiment.
$\mathrm{R}_{\text {chiral }}=\mathrm{R}_{\mathrm{D}} / \mathrm{R}_{\mathrm{L}}$

Evidently, when $\mathrm{R}_{\text {chiral }}=1$ there is no chiral discrimination, which denotes that this specific array of metal and chiral reference is not able to originate effective enantiomeric distinction under these specific conditions. Therefore, the best systems to be selected are those ones that provide $\mathrm{R}_{\text {chiral }}$ as far as possible from unity, provided that accurate abundance ratios can still be measured. It must be mentioned, however, that the selection of adequate systems for enantiomeric distinction has been exclusively performed, as recently reported in literature, ${ }^{13,16,19}$ based on an alternative procedure, i.e. the mass-selection and fragmentation of the trimeric complexes $\left[\mathrm{M}\left(\mathrm{ref}^{*}\right)_{2}\left(\mathrm{~A}_{\mathrm{DL} L}\right)\right.$ $\mathrm{H}]^{+}$instead $\left[\mathrm{M}\left(\mathrm{ref}^{*}\right)\left(\mathrm{A}_{\mathrm{DL}()_{2}}\right)_{2}-\mathrm{H}\right]^{+}$. In such a case, the trimeric complexes $\left[\mathrm{M}(\mathrm{ref} *)_{2}\left(\mathrm{~A}_{\mathrm{D}(\mathrm{L})}\right)-\mathrm{H}\right]^{+}$dissociate competitively to form the dimeric complexes $\left[\mathrm{M}\left(\mathrm{ref}^{*}\right)\left(\mathrm{A}_{\mathrm{D}(\mathrm{L})}\right)-\mathrm{H}\right]^{+}$and $\left[\mathrm{M}\left(\mathrm{ref}^{*}\right)_{2}-\mathrm{H}\right]^{+}$by the loss of the neutral reference compound (ref*) and analyte (A), respectively, and the $\mathrm{R}_{\text {chiral }}$ can be obtained.

The enantiomeric composition of a chiral analyte solution is determined founded on a linear relationship between the natural logarithm of the abundance ratios $\mathrm{R}$ $\left.\left.\left(\mathrm{R}=\left[\mathrm{M}\left(\mathrm{ref}^{*}\right)(\mathrm{A})-\mathrm{H}\right]^{+}\right] / \mathrm{M}(\mathrm{A})_{2}-\mathrm{H}\right]^{+}\right)$and the analyte enantiomeric excess (ee). This relationship can be obtained from the equation of the kinetic method (equation 4): ${ }^{13,16}$

$\ln (\mathrm{R})=\Delta(\Delta \mathrm{G}) / \mathbf{R T}_{\text {eff }}=\left(\Delta \mathrm{G}_{\mathrm{D}}-\Delta \mathrm{G}_{\mathrm{L}}\right) / \mathbf{R T}_{\text {eff }}$

where $\mathrm{T}_{\text {eff }}$ is the average effective temperature of the two activated complexes for the two competitive reactions and $\mathbf{R}$ is the gases constant. This equation says that the natural logarithm of the ratio $\mathrm{R}$ is proportional to the difference in free energy, $\Delta(\Delta \mathrm{G})$, for the formation of the two diasteromeric ions $\left[\mathrm{M}\left(\mathrm{ref}^{*}\right)\left(\mathrm{A}_{\mathrm{D}}\right)-\mathrm{H}\right]^{+}$and $\left[\mathrm{M}\left(\mathrm{ref}^{*}\right)\left(\mathrm{A}_{\mathrm{L}}\right)\right.$ $\mathrm{H}]^{+}$(Scheme 2). When the analyte sample is made up of the pure $\mathrm{D}$ or L enantiomers, $\Delta(\Delta \mathrm{G})$ becomes $\Delta \mathrm{G}_{\mathrm{D}}$ or $\Delta \mathrm{G}_{\mathrm{L}}$, respectively (Scheme 2). For an enantiomeric mixture with an excess of enantiomer $\mathrm{D}$, for example, one can write (equation 5):

$\Delta(\Delta \mathrm{G})=\left(\Delta \mathrm{G}_{\mathrm{D}}\right)(1+$ ee $) / 2+\left(\Delta \mathrm{G}_{\mathrm{L}}\right)(1-$ ee $) / 2=\left[\left(\Delta \mathrm{G}_{\mathrm{D}}\right)+\right.$ $\left.\left(\Delta \mathrm{G}_{\mathrm{L}}\right)\right] / 2+\left[\left(\Delta \mathrm{G}_{\mathrm{D}}\right)-\left(\Delta \mathrm{G}_{\mathrm{L}}\right)\right] \times \mathrm{ee} / 2$

Moreover, the combination of equations 4 and 5 furnishes an expression describing a linear relationship between the enantiomeric excess (ee) and $\ln (\mathrm{R})$ as shown in equation 6 :

$\ln (R)=\left[\left(\Delta G_{D}\right)+\left(\Delta G_{L}\right)\right] / 2 R_{\text {eff }}+\left[\left(\Delta G_{D}\right)-\left(\Delta G_{L}\right)\right] * e / 2 R_{\text {eff }}$ 
Thus, unknown enantiomeric mixtures are then analysed by measuring the ratio of the two fragment ions, i.e. $\left.\left[\mathrm{M}\left(\mathrm{ref}^{*}\right)(\mathrm{A})-\mathrm{H}\right]^{+}\right]$and $\left.\left.\mathrm{M}(\mathrm{A})_{2}-\mathrm{H}\right]^{+}\right)$, in a single tandem mass spectrum. This methodology is already wellestablished and known as the single ratio method. ${ }^{12}$

The aim of this paper is, therefore, to apply the kinetic method strategy to determine the enantiomeric composition of pantothenic acid solutions, an important substance for the pharmaceutical and food industries. As chiral reference compounds, a series of $\alpha$-hydroxyacids (L-tartaric acid, L-lactic acid, L-3-phenyl lactic acid, L-citramalic acid, L-mandelic acid, L-malonic acid, L-citric acid), sugars (D-glucose, D-mannose, D-galactose), aminoacids (L-Pro, L-Trp, L-Ala, L-Arg, L-Val, L-Tyr, L-Glu, L-Phe, L-Cys, L-Leu, L-His, L-Lys), and modified aminoacids (N-t-Boc-LPro, N-t-Boc-L-Phe or N-Fmoc-L-Pro) were tested in order to select the best system for chiral recognition and quantitation. These references were chosen since (a) they can be easily obtained in enantiomerically pure form; and (b) in previous studies, some of these compounds proved to be useful as reference compounds in chiral analysis. ${ }^{15,17,18}$ Four divalent metal cations $\left(\mathrm{M}=\mathrm{Ca}^{2+}, \mathrm{Cu}^{2+}, \mathrm{Ni}^{2+}, \mathrm{Zn}^{2+}\right)$ were selected as the central metal ions owing to their well-known ability to form complexes with oxygen and nitrogencontaining compounds, as well as to their recent use in chiral analysis of several compounds by the kinetic method. ${ }^{13,15-19}$

\section{Experimental}

All experiments were performed using a commercial LCQ Advantage ion trap mass spectrometer (Thermo
Finnigan, San Jose, CA), equipped with an ESI source and operated in the positive ion mode. The mass spectra reported are the average of about 40 scans, each requiring $0.2 \mathrm{~s}$. Samples were infused into the ESI source via a syringe pump at a flow rate of $2.00 \mu \mathrm{L} \mathrm{min}^{-1}$. Typical ESI conditions were as follow: heated capillary temperature, $150{ }^{\circ} \mathrm{C}$; sheath gas $\left(\mathrm{N}_{2}\right)$ flow rate, $0.75 \mathrm{~L} \mathrm{~min}^{-1}$; spray voltage $5 \mathrm{kV}$; capillary voltage $3 \mathrm{~V}$; tube lens off set voltage, $40 \mathrm{~V}$. The aqueous methanol 1:1 solutions were prepared by the mixture of the following reagents: (a) $2 \times 10^{-5} \mathrm{~mol} \mathrm{~L}^{-1}$ of calcium pantothenate, the calcium salt of pantothenic acid (in these experiments it was used the pure D-enantiomer and the racemic mixture of such reagent); (b) $2 \times 10^{-5} \mathrm{~mol} \mathrm{~L}^{-1}$ of a chiral reference compound (ref*) such as: $\alpha$-hydroxyacids (L-tartaric acid, L-lactic acid, L-3-phenyl lactic acid, L-citramalic acid, L-mandelic acid, L-malonic acid, L-citric acid), sugars (D-glucose, D-mannose, D-galactose), aminoacids (L-Pro, L-Trp, L-Ala, L-Arg, L-Val, L-Tyr, L-Glu, L-Phe, L-Cys, L-Leu, L-His, L-Lys), and modified aminoacids (N-t-Boc-L-Pro, N-t-Boc-L-Phe or N-Fmoc-LPro); and (c) $2 \times 10^{-5} \mathrm{~mol} \mathrm{~L}^{-1}$ of a metal cation (nitrate salt of $\left.\mathrm{Ca}^{2+}, \mathrm{Cu}^{2+}, \mathrm{Ni}^{2+}, \mathrm{Zn}^{2+}\right)$.

\section{Results and Discussion}

Figure 1 shows the ESI-MS spectrum of a solution containing calcium D-pantothenate and N-Fmoc-L-Pro. The formation of the trimeric complex [Ca(N-Fmoc-LPro)(D-pantacid $\left.)_{2}-\mathrm{H}\right]^{+}(\mathrm{m} / \mathrm{z}, 814)$ is observed and indicated in this spectrum. Note that several other ionic adducts, such as $[\mathrm{D} \text {-pantacid }+\mathrm{H}]^{+}(\mathrm{m} / \mathrm{z}, 220)$, [Ca(NFmoc-L-

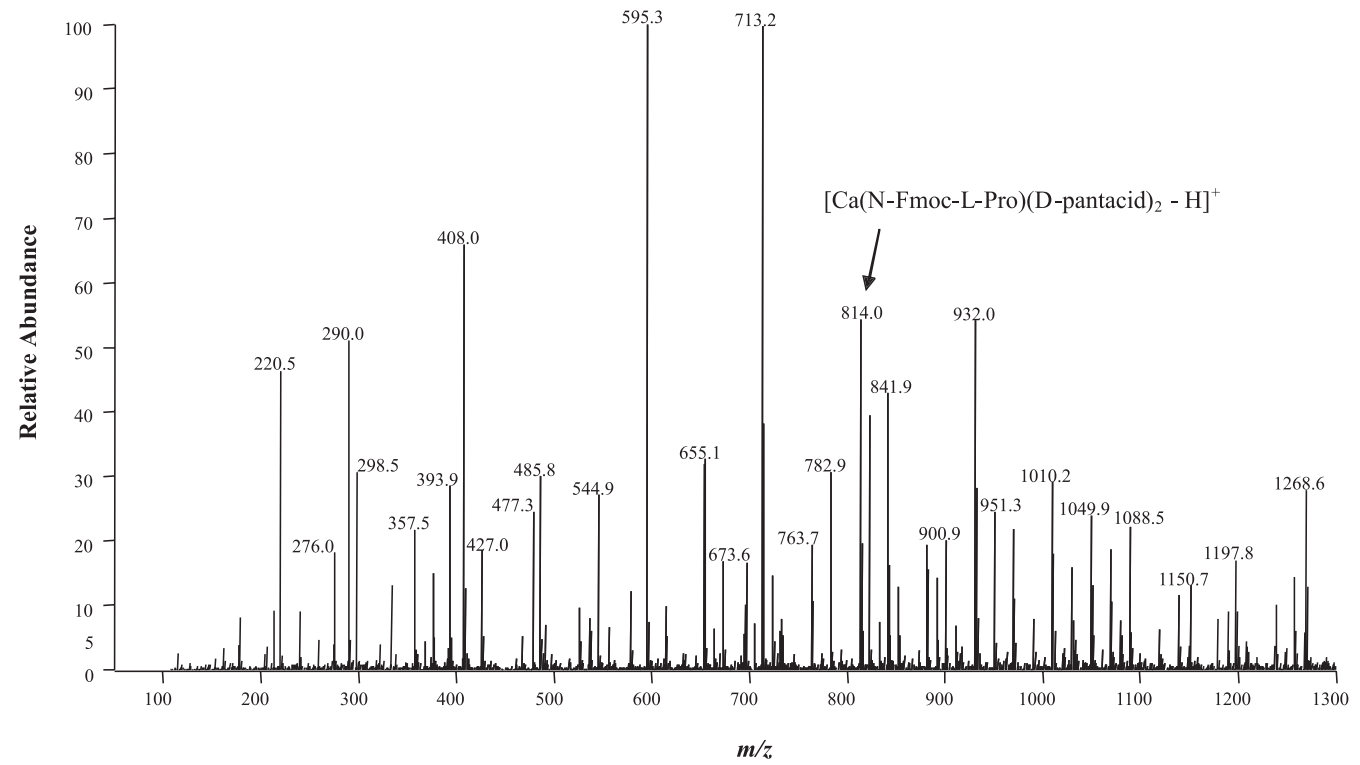

Figure 1 - ESI-MS spectrum of the aqueous methanol 1:1 solution containing calcium D-panthotenate $2 \times 10^{-5}$ mol $\mathrm{L}^{-1}$ and the modified aminoacid N-Fmoc-L-Pro $2 \times 10^{-5} \mathrm{~mol} \mathrm{~L}{ }^{-1}$. The presence of the trimeric complex $\left[\mathrm{Ca}(\mathrm{N}-\mathrm{Fmoc}-\mathrm{L}-\mathrm{Pro})(\mathrm{D}-\mathrm{pantacid}){ }_{2}-\mathrm{H}\right]^{+}(\mathrm{m} / z, 814)$ is indicated in this spectrum. 
Pro $)($ pantacid $\left.)-\mathrm{H}]^{+}(\mathrm{m} / \mathrm{z} \text { 595), [Ca(NFmoc-L-Pro })_{2}-\mathrm{H}\right]^{+}$ $(\mathrm{m} / 2713)$, and the trimeric complex $\left[\mathrm{Ca}(\mathrm{N}-\mathrm{Fmoc}-\mathrm{L}-\mathrm{Pro})_{2}(\mathrm{D}-\right.$ pantacid $)-\mathrm{H}]^{+}(\mathrm{m} / \mathrm{z}$ 932), are also detected in such spectrum.

Figure 2 ( $\mathrm{a}$ and $\mathrm{b}$ ) shows the collision-induced dissociation spectrum of the mass-selected trimeric complexes $\left[\mathrm{Ca}(\mathrm{N}-\mathrm{Fmoc}-\mathrm{L}-\mathrm{Pro})(\mathrm{D}-\text { pantacid })_{2}-\mathrm{H}\right]^{+}$(formed in the solution containing pure D-pantothenic acid) and $\left[\mathrm{Ca}(\mathrm{N}-\mathrm{Fmoc}-\mathrm{L}-\mathrm{Pro})(\mathrm{DL}-\text { pantacid })_{2}-\mathrm{H}\right]^{+}$(from a solution with racemate pantothenic acid), respectively. The $\mathrm{R}_{\text {chiral }}$ for this system, calculated by using equation 3 , was found to be 0.71 and reflects the difference in stability of the diastereomeric ions $[\mathrm{Ca}(\mathrm{N}-\mathrm{Fmoc}-\mathrm{L}-\mathrm{Pro})(\mathrm{D}-\text { pantacid })-\mathrm{H}]^{+}$ and $\left[\mathrm{Ca}(\mathrm{N}-\mathrm{Fmoc}-\mathrm{L}-\mathrm{Pro})(\mathrm{L}-\text { pantacid) }-\mathrm{H}]^{+}\right.$.
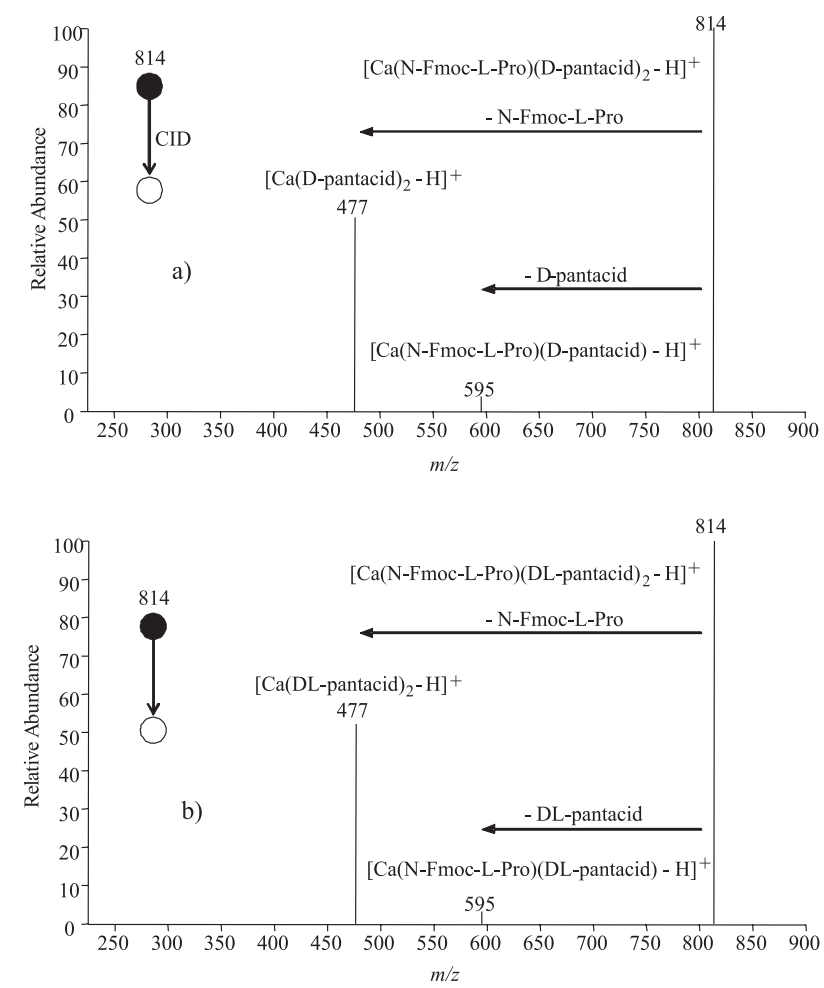

Figure 2 - MS/MS product ion spectra of (a) $[\mathrm{Ca}(\mathrm{N}-\mathrm{Fmoc}-\mathrm{L}-\mathrm{Pro})(\mathrm{D}$ pantacid $\left.)_{2}-\mathrm{H}\right]^{+}\left(\mathrm{m} / z\right.$ 814) and (b) $\left[\mathrm{Ca}(\mathrm{N}-\mathrm{Fmoc}-\mathrm{L}-\mathrm{Pro})\left(\mathrm{DL}-\right.\right.$ pantacid) ${ }_{2}$ $-\mathrm{H}]^{+}(\mathrm{m} / \mathrm{z}$ 814). The CID activation level is chosen as $10.6 \%$, corresponding to approximately $265 \mathrm{mV}$ AC.

The ratio $\mathrm{R}_{\mathrm{L}}\left(\mathrm{R}_{\mathrm{L}}=[\mathrm{Ca}(\mathrm{N}-\mathrm{Fmoc}-\mathrm{L}-\mathrm{Pro})(\mathrm{L}-\right.$ pantacid $)$ $\left.\mathrm{H}]^{+} /\left[\mathrm{Ca}(\mathrm{L}-\text { pantacid })_{2}-\mathrm{H}\right]^{+}\right)$, which determination is necessary to calculate $\mathrm{R}_{\text {chiral }}$, is related to the dissociation of the trimeric complex $\left[\mathrm{Ca}(\mathrm{N}-\mathrm{Fmoc}-\mathrm{L}-\mathrm{Pro})(\mathrm{L}-\text { pantacid })_{2}\right.$ $\mathrm{H}]^{+}$(hypothetically formed in a solution containing pure L-pantothenic acid) and is obtained by extrapolation to zero in a plot of $\ln (\mathrm{R})$ versus the molar fraction of $\mathrm{D}$ pantothenic acid, as shown in Figure 3.

Curiously, the trimeric complex [Ca(N-Fmoc-LPro) ${ }_{2}$ (pantacid) - $\left.\mathrm{H}\right]^{+}(\mathrm{m} / z$, 932), which could alternatively be used for such chiral distinction (see some considerations about it in Introduction section), did not produce a

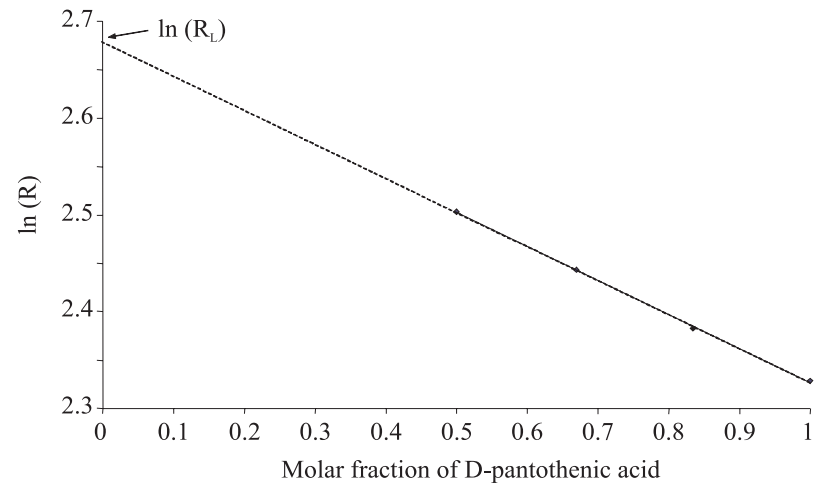

Figure 3 - Calibration curve for chiral analysis of pantothenic acid using $\mathrm{Ca}^{2+}$ as the metal cation and N-Fmoc-L-Pro as the chiral reference compound. The chiral selectivity factor $\left(\mathrm{R}_{\text {chiral }}\right)$ is 0.71 and the correlation coefficient $\left(\mathrm{R}^{2}\right)$ is 0.9995 . Each point represents an average of ten measurements.

convenient value for $\mathrm{R}_{\text {chiral }}$. Moreover, the use of other systems, i.e. different combinations of the reference compounds and metal cations cited in the Experimental section, did not furnish satisfactory results for the chiral recognition of pantothenic acid solutions. This was caused by at least one among the following reasons: (a) no formation of the required trimeric complexes $\left[\mathrm{M}\left(\mathrm{ref}^{*}\right)(\mathrm{A})_{2}\right.$ $-\mathrm{H}]^{+}$or $\left[\mathrm{M}\left(\mathrm{ref}^{*}\right)_{2}(\mathrm{~A})-\mathrm{H}\right]^{+}$; (b) no production of both dimeric ions during the dissociation of such trimeric complexes; and (c) systems with $R_{\text {chiral }}$ very close to unit.

A linear relationship between $\ln (\mathrm{R}), \mathrm{R}=[\mathrm{Ca}(\mathrm{N}-\mathrm{Fmoc}-$ L-Pro)(pantacid) $-\mathrm{H}]^{+} /\left[\mathrm{Ca}(\text { pantacid })_{2}-\mathrm{H}\right]^{+}$), versus the molar fraction of D-pantothenic acid is observed with an excellent correlation coefficient $\left(R^{2}=0.9995\right)$ (Figure 3$)$. The ratio $R$ for any solution containing $\mathrm{Ca}^{2+}$, N-Fmoc-L-Pro, and panthotenic acid can be easily determined by measuring the intensities of the dimeric complexes $[\mathrm{Ca}(\mathrm{N}-\mathrm{Fmoc}-\mathrm{L}-$ Pro)(pantacid) $-\mathrm{H}]^{+}\left(\mathrm{m} / \mathrm{z}\right.$ 595) and $\left[\mathrm{Ca}(\text { pantacid })_{2}-\mathrm{H}\right]^{+}(\mathrm{m} / \mathrm{z}$ 477) formed from the dissociation of the mass-selected trimeric complex $\left[\mathrm{Ca}(\mathrm{N}-\mathrm{Fmoc}-\mathrm{L}-\mathrm{Pro})(\text { pantacid })_{2}-\mathrm{H}\right]^{+}(\mathrm{m} / \mathrm{z}$ 814 ), as exemplified in Figures $2 \mathrm{a}$ and $2 \mathrm{~b}$. Using the calibration curve in Figure 3, the enantiomeric composition of prepared solutions of pantothenic acid was determined and outstanding results were obtained, as illustrated by the data of Table 1. Significantly, it was verified that the relative

Table 1. Actual and experimental values for the enantiomeric composition of pantothenic acid solutions

\begin{tabular}{ccc}
\hline \multicolumn{3}{c}{ Fraction of D-pantothenic acid (\%) } \\
\hline Actual & Experimental $^{\mathrm{a}, \mathrm{b}}$ & Difference \\
\hline 60 & $61 \pm 2$ & 1 \\
80 & $82 \pm 1$ & 2 \\
90 & $91 \pm 1$ & 1 \\
\hline
\end{tabular}

aalues obtained from the calibration curve (Figure 3); ${ }^{\mathrm{b}}$ Average of ten measurements ( $95 \%$ confidence interval). 
concentrations of pantothenic acid vs. N-Fmoc-L-Pro did not affect the chiral discrimination in these systems. ${ }^{16,20}$ This is an indispensable result for successful quantitative analysis of unknown samples.

\section{Conclusions}

The subject reported in this paper is of wide relevance, particularly to the pharmaceutical and food industries, both for the general demonstration of a simple method of enantiomer quantitation and in particular because pantothenic acid represents a valuable substance with improved possibilities of application. Furthermore, the present study demonstrates for the first time that $\mathrm{Ca}^{2+}$, a non-transition metal previously tested in similar chiral recognition experiments, ${ }^{21}$ has a better performance than transition metal cations, such as $\mathrm{Cu}^{2+}, \mathrm{Ni}^{2+}, \mathrm{Zn}^{2+}$. The results presented herein demonstrate that not only $\left[\mathrm{M}\left(\mathrm{ref}^{*}\right)_{2}(\mathrm{~A})\right.$ $\mathrm{H}]^{+}$but also $\left[\mathrm{M}\left(\mathrm{ref}^{*}\right)(\mathrm{A})_{2}-\mathrm{H}\right]^{+}$trimeric complexes can be used for chiral quantitation by the single ratio method. It can also be envisioned that once the linearity of the semilog plot has been established for a chiral analysis, a twopoint calibration curve would allow a faster but still reliable method of quantitative chiral analysis. By the use of a two-point calibration curve, which could be built by using the D-enantiomer and the racemic mixture of pantothenic acid, the enantiomeric composition of unknown solutions could be determined in a quick, but still reliable, way.

\section{Acknowledgements}

The authors thank Conselho Nacional de Desenvolvimento Científico e Tecnológico (CNPq) and Fundação de Amparo à Pesquisa do Estado de Minas Gerais (FAPEMIG) for financial support. The authors are also indebt to Dr. Tânia Maria de Almeida Alves and Dr. Carlos Zani (Centro de Pesquisas René Rachou - Fundação Osvaldo Cruz) for their consent in using the mass spectrometer.

\section{References}

1. Stryer, L.; Biochemistry, $4^{\text {th }}$ revised ed.; Spektrum: Heidelberg, Germany, 1996.

2. Stinson, S. C.; Chem. Eng. News 2000, 78, 55.

3. Grigorean, G.; Ramirez, J.; Ahn, S. H.; Lebrilla, C. B.; Anal. Chem. 2000, 72, 4275.

4. Sawada, M.; Mass Spectrom. Rev. 1997, 16, 73.

5. Nikolaev, E. N.; Denisov, E. V.; Rakov, V. S.; Futrell, J. H.; Int. J. Mass Spectrom. 1999, 183, 357.

6. Grigorean, G.; Lebrilla, C. B.; Anal. Chem. 2001, 73, 1684.

7. Smith, G.; Leary, J. A.; J. Am. Chem. Soc. 1996, 118, 3293.

8. Cooks, R. G.; Kruger, T. L.; J. Am. Chem. Soc. 1977, 99, 1279.

9. Cooks, R. G.; Patrick, J. S.; Kotiaho, T.; McLuckey, S. A.; Mass Spectrom. Rev. 1994, 13, 287.

10. Cooks, R. G.; Wong, P. S. H.; Acc. Chem. Res. 1998, 31, 379.

11. Cooks, R. G.; Koskinen, J. T.; Thomas, P. D.; J. Mass Spectrom. 1999, 34, 85 .

12. Zheng, X.; Augusti, R.; Tao, W. A.; Cooks, R. G. In The Encyclopedia of Mass Spectrometry, $1^{\text {st }}$ ed.; Gross, M. L.; Caprioli, R. M., eds., Elsevier: Burlington MA, 2003, Vol. 1, pp. $350-362$

13. Tao, W. A.; Zhang, D.; Nikolaev, E. N.; Cooks, R. G.; J. Am. Chem. Soc. 2000, 122, 10598.

14. Tao, W. A.; Zhang, D.; Wang, F.; Thomas, P.; Cooks, R. G.; Anal. Chem. 1999, 71, 4427.

15. Tao, W. A.; Wu, L.; Cooks, R. G.; Chem. Commun. 2000, 20, 2023.

16. Augusti, D. V.; Carazza, F.; Augusti, R.; Tao, W. A.; Cooks, R. G.; Anal. Chem. 2002, 74, 3458

17. Tao, W. A.; Gozzo, F. C.; Cooks, R. G.; Anal. Chem. 2001, 73, 1692 .

18. Tao, W. A.; Wu, L.; Cooks, R. G.; Wang, F.; Begley, J. A.; Lampert, B.; J. Med. Chem. 2001, 44, 3541.

19. Augusti, D. V.; Augusti, R.; Carazza, F.; Cooks, R. G.; Chem. Commun. 2002, 19, 2242.

20. Zhang, D.; Tao, W. A.; Cooks, R. G.; Int. J. Mass Spectrom. 2001, 204, 159 .

21. Tao, W. A.; Cooks, R. G.; Anal. Chem. 2003, 1, 25A.

Received: October 28, 2003 Published on the web: September 3, 2004 